\title{
Financial Management in Non-Profit Organisations: An Exploratory Study
}

\section{Barry Strydom}

\author{
Senior Lecturer, School of Accountancy, Economics and Finance, University of KwaZulu-Natal
}

Email: strydomb@ukzn.ac.za

Tim Stephen

Project Leader, Investec South Africa,

Email:Tim.Stephen@Investec.co.za

Doi:10.5901/mjss.2014.v5n15p55

\begin{abstract}
The recent financial crisis resulted in a sharp decline in donor funding that caused severe financial difficulties for many nonprofit organisations (NPO). This study examined whether or not NPOs employed sound financial management practices and whether the use of financial management practices has affected non-profit organisations' ability to survive the difficult economic climate. A survey was conducted of a sample of NPOs located in Pietermaritzburg. The study found that the majority of NPOs surveyed utilised recommended financial management principles but that there was no statistical relationship between their use and the experience of financial distress. It was found that having sufficient reserves and the existence of a separate finance committee were significant aspects related to the absence of financial distress. Further, evidence was found to suggest that the size and age of the NPO, as well as the experience of its financial manager, were significant factors in whether or not financial distress was experienced.
\end{abstract}

Keywords: Non-profit organisations, financial management, budgeting, cash management, financial distress

\section{Introduction}

Globally the importance of non-profit organisations (NPOs) in economic and social development has grown with a major shift in development funding occurring from government agencies to non-government organisations (NGOs) (Goddard and Assad, 2006: 377). NPOs have a key role to play in tackling the monumental challenge of social development in South Africa (Conradie, 1999: 291). The NPO sector in South Africa is substantial with 56237 registered NPOs in 2009 (Department of Social Development, 2009: 7) and total income in 2004 estimated at R14 billion (Department of Social Development, 2005: 30). A 2002 Johns Hopkins report on the size and scope of the non-profit sector in South Africa finds that in combating poverty NPOs make a significant positive impact at a community level due to their ability to respond quickly and efficiently to problems at a community level (Department of Social Development, 2005: 30). The importance of NPOs, however, is especially felt when they get into financial difficulty and are forced to cease operations with the associated detrimental effect on those who have benefited from their work and those who work with the organisation (Conradie, 1999: 291).

Due to their reliance on external funding, NPOs are likely to encounter serious capacity problems as a result of a decline in social welfare spending (LeRoux, 2005: 351). The recent financial crisis has resulted in just such a sharp decline in donor funding, presenting severe financial challenges for many NPOs. Financial management is critical for the economic sustainability of an NPO (Pajas and Vilain, 2004: 342) and the current reduction in available funding has highlighted the importance of financial management for the sustainability of NPOs in a difficult economic environment (York, 2009: 1). Grønbjerg et al. (2007: 7), however, report that financial management is one of the most challenging areas that managers of NPOs have to deal with. Relatively little research has been conducted on the financial management of NPOs, particularly in South Africa. This study seeks to provide a starting point for the possibility of investigating the management of NPOs by exploring the possibilities for research in this important area. This paper thus seeks to investigate the extent to which NPOs in the Pietermaritzburg area apply recommended financial management practices, the impact that the financial crisis has had on them and whether or not a relationship exists between the NPOs' application of sound financial management and their financial vulnerability. 


\section{Financial Management and NPOs}

\subsection{The Goal of Financial Management}

The generally accepted goal of for-profit financial management is maximising shareholder wealth through increasing the share price of the company. Typically, this involves maximising risk-adjusted profits through increasing revenues or reducing costs, or both (Zietlow, Hankin and Seidner, 2007: 11). In the context of an NPO which does not have shareholders and which has as its goal delivering services to those in need, rather than making profits, the standard model of financial management is clearly not appropriate. Krug and Weinberg (2004: 325), therefore, describe the goal of financial management for NPOs as ensuring that revenues can be maintained while delivering essential purposes. Copeland and Smith (1978) suggest that NPOs that are donor funded (which describes most of the NPOs surveyed in this study) have the primary objective of 'donor utility maximisation', namely to ensure that the resources provided by the donor are utilised in the most efficient manner possible. Zietlow et al. (2007: 12), in a study of 288 faith-based organisations in the United States between 1992 and 1994, find that 38.5\% state that 'financial break-even' is their primary financial objective with $20.5 \%$ identifying 'maximising net revenues' as their main financial objective. They further note that "... as a secondary objective respondents indicated a concern for cost minimization (11.8\%), avoiding financial risk (8.6\%), and maximising net donations (6.9\%)". It can thus be seen that the goal of financial management for an NPO, namely survival or the minimisation of deficits rather than maximising revenue, differs significantly from a for-profit organization (Krug and Weinberg, 2004: 334). This fundamental difference is likely also to result in differences in the practice of financial management in an NPO setting.

\subsection{The Scope of Financial Management for NPOs}

Financial management is generally divided into three broad categories, namely capital structure, capital budgeting and short-term financial management (also referred to as working capital management). An NPO, however, typically does not generate its own income and relies on external sources for its funding, making debt, with its commitment to monthly interest repayments, extremely risky and hence undesirable (C. Masters, CEO of C Masters Development Services (CMDS), personal communication, 10 June 2010). In addition, an NPO does not have shareholders and hence its capital structure does not include a substantial equity component and so the relevance of capital structure theory for NPOs is limited. Unlike capital structure, capital budgeting can "...have a dramatic impact on the character of an NPO for many years since they often involve the commitment of extensive resources over a long period of time" (Gaertner, 1982: 46). This paper, however, seeks to examine the impact of the global financial recession on NPOs' financial viability, which is a function of their ability to meet short-term financial commitments. As a result this study focuses specifically on short-term financial management.

\subsection{Short-Term Financial Management for NPOs}

Short-term financial management involves decisions that affect current assets and liabilities, usually involving cash inflows and outflows occurring within the next twelve months, and comprises cash management, inventory management and accounts receivable management. For most NPOs the issues of inventory management and accounts receivable management are likely to be less significant but the forecasting/budgeting of future cash requirements and management of cash is critical.

\subsubsection{Budgeting and Forecasting}

Budgeting is seen as one of the most challenging areas of managing an organisation's finances (Hankin, Seidner and Zietlow, 1997: 147). One of the chief advantages of budgeting for an NPO is that if planned and executed properly, the likelihood of the NPO being economically sustainable is improved (Blazek, 2008: 71). In the 1970s, it was common practice to advocate zero-base budgeting (ZBB), which requires managers to justify their entire budgets each year with no base level of spending being assumed, but it was found to be extremely time consuming and is seldom used (Anthony and Young, 1999: 453). The incremental approach treats existing programmes as preapproved, subject only to changes in financial resources allocated, which means that it is less time consuming and is also felt to be less threatening to managers of programmes (Blazek, 2008: 69). Gambino and Reardon (1981 cited in Zietlow, 1989: 220) note that with regards to the well-established NPOs in their study, the use of budgeting and forecasting in particular was generally poor. 
Zietlow (1989: 225), in an empirical analysis of 47 NPOs, finds that seven prepared no budgets whatsoever, and of those that do prepare budgets, less than half indicate that they even attempted to utilise ZBB.

\subsubsection{Management of Cash Resources}

Often, the most important resource for a NPO is its cash (Blazek, 2008: 107). Zietlow and Seidner (2007: 13) suggest that the primary objective of NPOs should be striving to meet an "approximate liquidity target" over time. By doing so, a sound cash flow management system can assist an organisation to survive any periods of strain or uncertainty. Cash management is, thus, often used as an important indicator of the "fundamental health" of an NPO, with Pajas and Vilain (2004: 352) suggesting that, because NPOs usually do not worry about maximising their profits but do need cash to operate, cash management is even more important for the nonprofit sector.

\subsubsection{Performance Analysis}

Accountability is seen as the number one priority for NPOs, both to the people or cause it may support and to donors/funders who commit financial resources to the NPO. However, performance analysis is an area in which NPOs are particularly weak (Evans, 2010: 26, 27). Performance measurement can be multi-faceted, with two of the common techniques for NPOs being ratio analysis and variance analysis.

\subsubsection{Ratio Analysis}

Various ratios are used for both internal and external monitoring as "measurement of financial performance by ratio analysis helps identify organisational strengths and weaknesses by detecting financial anomalies and focusing attention on issues of organisational importance (Glynn et al. 2003, cited in Abraham, 2006: 1). Ratio analysis can thus be used as a control mechanism for long-run targeting (Zietlow, 1989: 226). Zietlow and Seidner (2007: 4), however, observe that the majority of NPOs do not use ratio analysis, a statement borne out by Zietlow's (1989: 225) finding that only 17\% of his respondents employed ratio analysis.

\subsubsection{Variance Analysis}

Pajas and Vilain (2004: 352) recommend using periodic reports to compare budgeted and actual revenues and expenses. This is usually done after a budget has been approved and allows for monitoring of expenditure (Blazek, 2008: 86). Anthony and Young (1999: 630) state that the "principal purpose of variance analysis is to facilitate the management control process", because if any significant differences arise, the NPO will be able to identify potential problems and make any necessary adjustments.

\section{Research Problem and Methodology}

\subsection{Research Problem and Main Objectives}

Given the important role that NPOs play in the sphere of social development, and in light of the recent global financial crisis, the issue of NPO financial management with regards to the efficiency and efficacy with which resources are utilised is an important one. Zietlow (1989: 228) finds that NPOs' use of key financial techniques increases with a) age; b) size; and $c$ ) their ability to hire or develop administrators with greater financial expertise. The objective of this research project is thus to investigate the use of financial management by NPOs in the Pietermaritzburg area and the extent to which these NPOs have been affected by the financial crisis given their use of financial management. The key research questions addressed were:

- the extent to which NPOs in the Pietermaritzburg area apply financial management practices;

- the relationship between demographic factors and NPOs' use of financial management is; and,

- whether or not a relationship exists between the NPOs' application of financial management practices and their financial vulnerability 


\subsection{Sample and Data Collection}

Data for this research project was collected using a survey administered in the greater Pietermaritzburg area over a period of three months - July to September 2010. A list of all the registered NPOs in the greater Pietermaritzburg area from 1997 to 2007 was extracted from the Department of Social Development database yielding an initial sample of 330 NPOs. The requirements for registration as an NPO, however, are relatively undemanding and so the list had to be filtered to ensure that it contained suitable candidates for the purpose of this research. Three criteria were applied to the NPOs, namely:

1. it operated to benefit society as a whole and not only members of the organisation;

2. it has its head office in the greater Pietermaritzburg area; and,

3. it had been operational for at least three years.

Criterion 1 has its basis in the focus on the role of NPOs in social upliftment and so organisations that did not conform to Bird's (1985: 161) classification of an NPO which "...confer[s] benefits on those beyond their own membership" were excluded. Criterion 2 was based on the practical constraints of time and money, which needed to keep the area of study manageable. Finally, criterion 3 allowed for the impact (if any) of the recent global financial crisis to be captured.

A combination of probability and non-probability sampling techniques was used in the research project. After the initial screening, the list was reduced to include the details of approximately 250 NPOs. Every fifth NPO was selected in an attempt to obtain a representative sample. Incorrect contact details meant that many NPOs could not be contacted while some NPOs were not willing to participate. As a result only sixteen useable responses were obtained through this process. Given the study's objective of examining the effect of the financial crisis on NPOs, the above sample would be subject to the problem of survivorship bias as only NPOs that are still operational appear on the Department of Social Development's database. In an attempt to mitigate survivorship bias, purposive sampling was then employed to include NPOs which had either ceased to operate or were facing imminent closure. Firstly, an expert in the sector with extensive experience in NPO-networking was consulted and several NPOs were included based on her recommendation. Secondly, a snowball technique was utilised to identify suitable NPOs by asking respondents to identify other NPOs that they knew had experienced financial distress. A further sixteen usable responses was obtained through this process of which seven had either ceased to operate or were facing imminent closure. This resulted in a total sample of 32 usable responses.

Based on a review of the literature on the financial management of NPOs, an initial questionnaire was drafted comprising five sections. Section 1 captured the general characteristics of the NPO including demographic details concerning staff responsible for its financial management. Section 2 analysed the financial management practice of the NPOs, while Section 3 interrogated the NPOs' funding sources. Section 4 examined how the NPOs allocate resources, and finally Section 5 examined the impact of the global financial crisis and the NPOs' use of reserves and debt finance.

\subsection{Method of Analysis}

Descriptive statistics were used to report the preliminary results of the survey. The fact that many of the responses to the survey questions resulted in ordinal data meant that non-parametric tests were required to analyse the relationship between responses. Specifically, the Chi-square test was used to test if two categorical variables were independent of each other. In those situations where a Chi-square test was not appropriate the Mann-Whitney test was employed to compare the means of samples. When comparisons were conducted between the distributions of two samples, including the median, dispersion, and skewness, the Kruskal-Wallis test was used.

\section{Findings and Analysis}

\subsection{Respondent Profiles}

The mean age of the NPOs in the sample was 8.16 years with all but two of the NPOs having been operational for five years or more since registration. The size of the NPOs was measured using two variables, namely total expenditure and the number of salaried employees, the results of which are presented below. 
Table 1: Size Characteristics of NPOs

\begin{tabular}{|c|c|c|c|c|c|}
\hline \multicolumn{7}{|c|}{ A. Total Annual Expenditure } \\
\hline & $<$ R1 million & R1 million <R5 million & > R5 million \\
\hline No. of NPOs & $9(28 \%)$ & \multicolumn{3}{c|}{$18(56 \%)$} & $5(16 \%)$ \\
\hline \multicolumn{7}{|c|}{ B. No. of Salaried Employees } \\
\hline & $0-9$ & $10-19$ & $20-39$ & $40-59$ & $>60$ \\
\hline No. of NPOs & $13(41 \%)$ & $9(27 \%)$ & $4(13 \%)$ & $3(9 \%)$ & $3(9 \%)$ \\
\hline
\end{tabular}

A distinction was made between the day-to-day financial activities of an NGO involving basic record keeping, and the financial management of the NPO's long-term financial strategy including budgeting and control. Table 2 presents the responses regarding who is responsible for these two aspects of financial management. Bookkeepers and administrators are seen to be the most common individuals responsible for the day-to-day financial activities of the NPOs. The financial management of the NPOs is seen to be predominantly executed by the Financial Manager or Director of the NPO.

Table 2: Individual(s) Responsible for Day-to-day Financial Activities and Financial Management

\begin{tabular}{|c|c|c|c|c|}
\hline & \multicolumn{2}{|c|}{ Day-to-day Financial Activities } & \multicolumn{2}{|c|}{ Financial Management } \\
\hline & Frequency & Percentage & Frequency & Percentage \\
\hline No one & 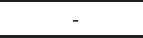 & - & 1 & 3.13 \\
\hline Director & 6 & 18.75 & 9 & 28.13 \\
\hline Finance Manager & 7 & 21.88 & 11 & 34.38 \\
\hline Bookkeeper & 9 & 28.13 & 1 & 3.13 \\
\hline Administrator & 8 & 25.00 & 3 & 9.38 \\
\hline Project manager & 2 & 6.25 & 2 & 6.25 \\
\hline Treasurer & - & - & 1 & 3.13 \\
\hline Board of Directors or Trustees & - & - & 3 & 9.38 \\
\hline Financial Agent & - & - & 1 & 3.13 \\
\hline Total & 32 & 100 & 32 & 100 \\
\hline
\end{tabular}

Table 3 below reports the educational qualifications and experience of the Financial Administrators of the NPOs relative to the size of the NPO.

Table 3: Educational Qualifications of Day-to-day Financial Administrator and NPO Size

\begin{tabular}{|l|c|c|c|c|c|}
\hline \multicolumn{1}{|c|}{ A. Qualification } & \multicolumn{3}{|c|}{ NPO's Total Expenditure of 2009 in Rands } & & \\
\hline & R0 - R1mil & R1.1mil - R5mil & $>5$ mil & Total & $\%$ \\
\hline Matric & 0 & 3 & 0 & 3 & 9.38 \\
\hline Certificate or Diploma & 3 & 9 & 3 & 15 & 46.88 \\
\hline Undergraduate Degree & 2 & 3 & 1 & 6 & 18.75 \\
\hline Postgraduate Degree & 2 & 2 & 0 & 4 & 12.50 \\
\hline Chartered Accountant & 2 & 1 & 1 & 4 & 12.50 \\
\hline Total & $\mathbf{9}$ & $\mathbf{1 8}$ & $\mathbf{5}$ & $\mathbf{3 2}$ & 100 \\
\hline B. Years' Experience & & & & & \\
\hline $0-4$ & 1 & 2 & 2 & 5 & 15.63 \\
\hline $5-9$ & 2 & 5 & 0 & 7 & 21.88 \\
\hline $10-19$ & 5 & 3 & 1 & 9 & 28.13 \\
\hline$>20$ & 1 & 8 & 2 & 11 & 34.38 \\
\hline Total & $\mathbf{9}$ & $\mathbf{1 8}$ & $\mathbf{5}$ & $\mathbf{3 2}$ & 100 \\
\hline
\end{tabular}

It is evident that all but three financial administrators have at least a certificate or diploma as their highest qualification with almost half (44\%) having a degree or higher qualification. Size does not seem to impact on the appointment of chartered accountants (CAs) - two of the four CAs are employed by small NPOs. The mean experience of Financial Administrators is 14.36 years while the median is 11 years indicating that the average day-to-day Financial Administrator has extensive experience in this area of work. A Kruskal-Wallis test found no significant difference between the 
educational qualifications or years of experience of Financial Administrators for different sized NPOs.

Table 4: Educational Qualifications of Financial Manager and NPO Size

\begin{tabular}{|c|c|c|c|c|c|}
\hline A. Qualification & \multicolumn{2}{|c|}{ NPO's Total Expenditure for 2009 in Rands } & & \\
\hline & R0 - R1mil & R1.1mil - R5mil & $>5$ mil & Total & $\%$ \\
\hline Matric & 0 & 1 & 0 & 1 & 3.13 \\
\hline Certificate or Diploma & 3 & 3 & 1 & 7 & 21.87 \\
\hline Undergraduate Degree & 2 & 7 & 2 & 11 & 34.38 \\
\hline Postgraduate Degree & 2 & 5 & 1 & 8 & 25.00 \\
\hline Chartered Accountant & 2 & 2 & 1 & 5 & 15.62 \\
\hline Total & 9 & 18 & 5 & 32 & 100 \\
\hline B. Years' Experience & & & & & \\
\hline $0-4$ & 1 & 3 & 1 & 5 & 15.63 \\
\hline $5-9$ & 2 & 3 & 0 & 5 & 15.63 \\
\hline $10-19$ & 4 & 5 & 2 & 13 & 40.62 \\
\hline$>20$ & 2 & 18 & 2 & 9 & 28.12 \\
\hline Total & $\mathbf{9}$ & & $\mathbf{5}$ & $\mathbf{3 2}$ & 100 \\
\hline
\end{tabular}

$75 \%$ of Financial Managers possess at least an undergraduate degree while almost $40 \%$ are either a Chartered Accountant or have a postgraduate degree. Financial Managers have a mean of 13.7 years' experience and median of 13.5 years. Again a Kruskal-Wallis test found no significant difference between the educational qualifications or years of experience of Financial Managers for different sized NPOs.

\subsection{Financial Management}

All NPOs included in the sample, including those who were found to not apply accepted Financial Management concepts, reported that they considered Financial Management to either be very important (6 respondents) or critical (26 respondents).

\subsubsection{Use of Finance Committee and Auditing of Financial Statements}

Table 5: Existence of Separate Finance Sub-Committee and NPO Size

\begin{tabular}{|l|c|c|c|c|}
\hline \multicolumn{1}{|c|}{ A. Size } & Whether Board has a Separate Finance Sub-committee & & \\
\hline & No & Yes & Total & $\%$ \\
\hline R0 - R1mil & 7 & 2 & 9 & 28.12 \\
\hline R1.1mil - R5mil & 9 & 9 & 18 & 56.25 \\
\hline$>$ 5mil & 0 & 5 & 5 & 15.63 \\
\hline Total & 16 & 16 & 32 & 100 \\
\hline B. Chi-Square Test & Critical Value & df & Asymp. Sig. (2-sided) \\
\hline \multicolumn{2}{|r|r}{} \\
\hline
\end{tabular}

Exactly $50 \%$ of the NPOs reported that they have a separate finance committee and $94 \%$ reported that they have their financial statements audited on an annual basis. It was found using a Chi-square test that at the $5 \%$ level of significance it was possible to conclude that the use of a separate Finance Committee is positively related to the size of the NPO. No significant relationship was found between the use of a separate Finance Committee and the qualification or experience of the Financial Manager.

\subsubsection{Use of Budgets}

No statistical relationship was found between the size of the organisation or Financial Manager's qualification and the types of budgets used. 29 of the NPOs (91\%) draw up a budget for the organisation as a whole. In addition to this overall budget, $22(70 \%)$ of the surveyed NPOs also draw up individual budgets for the various projects they are engaged in. Less important is the drawing up of divisional or departmental budgets, with only $7(22 \%)$ of the NPOs drawing up such 
budgets. Respondents were asked to list the reasons why they draw up budgets. Respondents were not limited in the number of reasons given, with the average respondent giving approximately two reasons. Table 6 shows that the two most popular reasons for drawing up budgets are that of monitoring and control and planning. Planning is put forth by Evans (2010) as the primary purpose of a budget as it specifies the expected levels of income and expenditure, however, less than half of the respondents (44\%) indicated explicitly that planning was a reason why they draw up budgets.

Table 6: Reasons for the Drawing up of Budgets

\begin{tabular}{|l|c|}
\hline \multicolumn{1}{|c|}{ Reason Given } & Count \\
\hline Monitoring and control & 25 \\
\hline Planning & 14 \\
\hline Fundraising & 9 \\
\hline Evaluation purposes & 5 \\
\hline Transparency and accountability & 5 \\
\hline We do not draw up budgets & 3 \\
\hline
\end{tabular}

As can be seen, 47\% (15 out of 32) of the NPOs reported that they make use of the ZBB approach while the remaining NPOs indicated that they favour the incremental approach. While this figure remains relatively low it is comparable with the results of Zietlow (1989) where less than half of the NPOs he surveyed made use of ZBB. The significance of various NPO characteristics in determining the use of ZBB was tested for using a Mann-Whitney $U$ test. The results are reported in table 7. It was found that the only characteristic which yielded a significant result at the $10 \%$ level was that of Director's experience and interestingly the relationship was found to be negative!

Table 7: Use of ZBB Compared to Various NPO Characteristics (Non-parametric Test)

\begin{tabular}{|l|c|c|c|c|c|}
\hline \multicolumn{1}{|c|}{ NPO Characteristics } & Mann-Whitney UWilcoxon W & Z & Asymp. Sig. (2-tailed) & Exact Sig. [2* (1-tailed Sig.)] \\
\hline Age of NPO (years) & 117.000 & 270.000 & -.403 & $\mathbf{0 . 6 8 7}$ & 0.710 \\
\hline Size of NPO (expenditure) & 117.00 & 270.00 & -0.444 & $\mathbf{0 . 6 5 7}$ & 0.710 \\
\hline Qualification Financial Manager & 112.50 & 232.50 & -0.585 & $\mathbf{0 . 5 5 9}$ & 0.576 \\
\hline Experience of Financial Manager & $\mathbf{1 2 3 . 0 0}$ & 243.00 & -0.171 & $\mathbf{0 . 8 6 4}$ & 0.882 \\
\hline Experience of Director & $\mathbf{7 8 . 0 0}$ & 198.00 & -1.888 & $\mathbf{0 . 0 5 9}$ & 0.064 \\
\hline
\end{tabular}

$75 \%$ of the respondents indicated that they draw up separate cash budgets. All those who indicated that they draw up cash budgets also indicated that they compare actual cash flows to budgeted cash flows on a regular basis (monthly or quarterly). A Chi-Square test found at the $5 \%$ level that the qualification of Financial Managers was a significant factor influencing the use of cash budgets indicating that less qualified Financial Managers were more likely to not employ cash budgeting.

Table 8: Financial Manager's Qualification and Usage of Cash Budgeting

\begin{tabular}{|l|c|c|c|c|}
\hline \multicolumn{1}{|c|}{ A. Qualification } & Whether NPO Draws Up Cash Budgets & & \\
\hline & No & Yes & Total & $\%$ \\
\hline Matric & 1 & 0 & 1 & 3.13 \\
\hline Certificate or Diploma & 4 & 3 & 7 & 21.88 \\
\hline Undergraduate Degree & 0 & 11 & 11 & 34.38 \\
\hline Postgraduate Degree & 1 & 7 & 8 & 25.00 \\
\hline Chartered Accountant & 1 & 4 & 5 & 15.63 \\
\hline Total & 7 & 25 & 32 & 100 \\
\hline B. Chi-Square test & Value & df & Asymp. Sig. (2-sided) \\
\hline & 12.168 & 4 & \multicolumn{3}{c|}{0.016} \\
\hline
\end{tabular}

\subsection{Financial Viability}

Respondents were asked if they had been late or had missed payments to creditors (including staff) over the last two years due to cash flow shortages. The period of two years was selected in order to capture the effects of the recent global 
financial crisis in late 2007. The results show that 15 of the NPOs included in the sample have been late and/or missed payments to creditors. The remaining 17 NPOs indicated that they have never missed a payment due to a creditor as a result of cash flow problems. Given that most NPOs reported using cash budgets and that they compare actual cash flows to budgeted cash flows, the fact that almost half the NPOs surveyed had missed a payment indicates that either their monitoring of their cash flows was not effective or that the reasons they were not able to make all payments on time was a result of factors beyond their control. Five NPOs indicated that they have been late and/or missed payments on one or two occasions. Eight responded that they had been late and/or missed payments on more than two occasions and, finally, two NPOs had ceased operations due to cash flow shortages. Not being able to make a payment on time was taken as an indicator of financial distress meaning that fifteen of the NPOs surveyed were categorised as Distressed and the remaining seventeen as Not Distressed.

Six key questions relating to different financial management concepts were included in the questionnaire, namely: use of organisational budgets; use of cash budgets; comparison of actual to budgeted cash flows; use of purchasing procedures; use of ratio analysis; and, targeted fundraising. To test the central hypothesis of the study, namely that the use of Financial Management concepts is related to an NPO's financial vulnerability, the relationship between financial status and the use of Financial Management concepts was tested using a Mann-Whitney $U$ test. As is evident from the results in Table 9 no statistically significant relationship was observed between NPOs' use of Financial Management concepts and their financial status. This result could suggest that the actual usage of the Financial Management concepts is not executed properly or that factors outside of the NPOs' control resulted in the financial distress.

Table 9: Distressed versus Not Distressed and Usage of Financial Management Concepts

\begin{tabular}{|c|c|c|c|c|}
\hline \multirow[t]{2}{*}{ A. No. of Concepts Used } & \multicolumn{4}{|c|}{$\begin{array}{l}\text { Overall Financial Management } \\
\text { Status }\end{array}$} \\
\hline & Distressed & Not Distressed & Total & $\%$ \\
\hline 0 & 2 & 0 & 2 & 6.25 \\
\hline 1 & 0 & 0 & 0 & 0.00 \\
\hline 2 & 1 & 0 & 1 & 3.13 \\
\hline 3 & 2 & 1 & 3 & 9.37 \\
\hline 4 & 1 & 3 & 4 & 12.50 \\
\hline 5 & 4 & 6 & 10 & 31.25 \\
\hline 6 & 5 & 7 & 12 & 37.50 \\
\hline Total & 15 & 17 & 32 & 100 \\
\hline \multicolumn{5}{|l|}{ B. Non-Parametric Test } \\
\hline Mann-Whitney U & 99.00 & & & \\
\hline Wilcoxon W & 219.00 & & & \\
\hline Z & -1.13 & & & \\
\hline Asymp. Sig. (2-tailed) & 0.260 & & & \\
\hline Exact Sig. [2*(1-tailed Sig.)] & 0.295 & & & \\
\hline
\end{tabular}

The relationship between various NPO characteristics and financial status was then analysed, the results being reported in Table 10 below. Age was found to be a significant factor with younger NPOs being more likely to have experienced financial distress in the period after the financial crisis. Similarly, a significant relationship, at the $5 \%$ level, was found between size and financial distress with smaller NPOs being more vulnerable to financial distress.

Table 10: Factors Related to Financial Status

\begin{tabular}{|c|c|}
\hline A. Ageof npo & \\
\hline Mann-Whitney U & 65.50 \\
\hline Wilcoxon W & 185.50 \\
\hline Z & -2.38 \\
\hline Asymp. Sig. (2-tailed) & 0.017 \\
\hline Exact Sig. [2*(1-tailed Sig.)] & 0.018 \\
\hline B. Size Of Npo & \\
\hline Mann-Whitney U & 63.00 \\
\hline Wilcoxon W & 183.00 \\
\hline
\end{tabular}




\begin{tabular}{|l|c|}
\hline Z & -2.73 \\
\hline Asymp. Sig. (2-tailed) & 0.006 \\
\hline Exact Sig. [2*(1-tailed Sig.)] & 0.014 \\
\hline \multicolumn{1}{|c|}{ C. Experience of Financial Manager } & 70.00 \\
\hline Mann-Whitney U & 190.00 \\
\hline Wilcoxon W & -2.18 \\
\hline Z & 0.029 \\
\hline Asymp. Sig. (2-tailed) & 0.030 \\
\hline Exact Sig. [2*(1-tailed Sig.)] & \\
\hline
\end{tabular}

Given that it is reasonable to expect that age and size should be related (Grønbjerg and Clerkin, 2004: 12), one must be cautious about interpreting these results as it is possible that the similar findings reflect this relationship between age and size. A Bi-variate Logit regression was therefore run using both age and size as explanatory variables of financial status. The model was found to be statistically significant with a Chi-square test statistic of 13.076 and a significance of 0.001 . The results of the model are reported in table 11 below.

Table 11: Bi-variate Logit analysis of Financial Status Using Age and Size as Explanatory Variables

\begin{tabular}{|cc|c|c|c|c|c|c|}
\hline & Variables in the Equation & B & S.E. & Wald & df & Sig. & Exp(B) \\
\hline \multirow{3}{*}{ Step 1a } & NPO_age_since reg & .411 & .218 & 3.556 & 1 & .059 & 1.509 \\
& total_expenditure & 1.942 & .886 & 4.807 & 1 & .028 & 6.972 \\
& Constant & -6.823 & 2.614 & 6.812 & 1 & .009 & .001 \\
\hline
\end{tabular}

a. Variable(s) entered on step 1: NPO_age_since reg, total_expenditure.

While the qualification of the Financial Manager was not found to be significant the Financial Manager's experience was significant with NPOs with less experienced Financial Managers more likely to suffer financial distress.

We further tested the relationship between sources of funding and financial status, as the source and mix of an NPO's funding has been found to affect the volatility of its income (Grønbjerg and Clerkin, 2004: 12). One might expect that NPOs that rely heavily on international donors for their funding are more susceptible to distress in difficult international economic times. The results in table 12 however, contradict this hypothesis. Of the ten NPOs that rely on international donors for $80 \%$ or more of their funding only $30 \%$ are Distressed, while of the sixteen NPOs that receive less than $20 \%$ of their funding from international donors, $50 \%$ are Distressed. In the Distressed group the mean percentage of reliance on international donor funding is $28 \%$, which is lower than the Not Distressed group's mean of $45 \%$. A MannWhitney $\mathrm{U}$ test, however, found no significant difference between the financial status of NPOs that rely on international funding and those that do not although it is possible that the failure to obtain a significant result is due to the small sample size. Smaller NPOs may also rely more on local donor funding than their larger counterparts which, as was reported, were less exposed to financial distress over the past two years.

Table 12: The Relationship Between Extent of International Funding and Financial Status

\begin{tabular}{|c|c|c|c|c|}
\hline & \multicolumn{2}{|c|}{ Overall Financial Management Status } & Total & $\%$ \\
\hline Percentage & Distressed & Not Distressed & 16 & 50.00 \\
\hline $0-19$ & 8 & 8 & 3 & 9.37 \\
\hline $20-39$ & 3 & 0 & 2 & 6.25 \\
\hline $40-59$ & 1 & 1 & 1 & 3.13 \\
\hline $60-79$ & 0 & 1 & 8 & 25.00 \\
\hline $80-99$ & 3 & 5 & 2 & 6.25 \\
\hline 100 & 0 & 2 & 32 & 100 \\
\hline Total & 15 & 17 & & \\
\hline
\end{tabular}

Finally, a comparison was made between the two groups according to five measures of financial control, namely: months of operating expenses held in reserve, the usage of purchasing procedures, cash budgeting, the usage of ratio analysis and the existence (or lack thereof) of a separate finance sub-committee. Table 13 summarises the results of this analysis. 
Table 13: The Relationship Between Operating Reserves and Financial Status

\begin{tabular}{|c|c|c|c|}
\hline A. Months of Operating Expenses in Reserve & $\mathbf{N}$ & Mean & Std. Deviation \\
\hline Distressed & 15 & 1.60 & 2.063 \\
\hline Not Distressed & 17 & 5.06 & 1.676 \\
\hline Mann-Whitney U & \multicolumn{3}{|c|}{27.00} \\
\hline Wilcoxon W & \multicolumn{3}{|c|}{147.00} \\
\hline & \multicolumn{3}{|c|}{-3.88} \\
\hline Asymp. Sig. (2-tailed) & \multicolumn{3}{|c|}{0.000} \\
\hline Exact Sig. [2*(1-tailed Sig.)] & \multicolumn{3}{|c|}{0.000} \\
\hline
\end{tabular}

Not surprisingly a considerable difference in the mean number of months' worth of operating expenses held in reserve by the Distressed and Not Distressed categories is observed, 1.60 months against 5.06 months. The Mann-Whitney U test confirms that a significant difference exists at the $1 \%$ significance level. Of course this analysis cannot identify causation; it is equally possible that firms encounter financial distress because they keep too few reserves or that they cannot afford to keep larger reserves because they are financially distressed.

As reported in Panel A of Table 14 no statistically significant relationship was found between NPOs' use of purchasing procedures and financial status. Similarly the results presented in Panel B reflect that the use of cash budgeting was not found to be significantly related to financial status. With regards to the use of ZBB, $60 \%$ of the Distressed NPOs indicated that they did not use ZBB whereas only $47 \%$ of the Not Distressed firms did not use ZBB but the difference was not statistically significant.

Approximately $40 \%$ of the NPOs make use of ratio analysis which compares favourably with the findings of Zietlow (1989) who reports that only $17 \%$ of the NPOs he sampled used ratio analysis, and Scarborough, Wilson and Zimmerer (2008) who find that $27 \%$ of the small businesses analysed utilised ratio analysis. The use of ratio analysis, however, was not found to be statistically significant in explaining NPOs' financial status.

Panel E shows that the majority of Distressed NPOs do not have a separate finance sub-committee while the majority of Not Distressed NPOs do have such a committee. A Chi-square test confirms a statistically significant difference between the financial status of NPOs employing such a committee and those that do not at a $1 \%$ level of significance. This finding provides evidence of the value of explicit board oversight of an NPO's financial performance rather than trusting in the ability of the Financial Manager to do so. However, as a significant relationship was also reported between NPO size and the use of a separate finance sub-committee it is also possible that this statistically significant result is simply capturing the effect of NPO size on financial status. A Bi-variate Logit regression was therefore run using both size and finance sub-committee as explanatory variables of financial status. The model was found to be statistically significant with a Chi-square test statistic of 14.068 and a significance of 0.001 . The results of the model are reported in table 15 below. The existence of a separate finance sub-committee remains a significant factor explaining financial status even controlling for size which is also significant at the $10 \%$ level.

Table 14: The relationship Between Cash Budgeting, Purchasing Procedures and Financial Status

\begin{tabular}{|c|c|c|c|}
\hline A. Use of Purchasing Procedures & No & Yes & Total \\
\hline Distressed & 1 & 14 & 15 \\
\hline Not Distressed & 7 & 10 & 17 \\
\hline Total & 8 & 24 & 32 \\
\hline & Value & $\mathrm{df}$ & Asymp. Sig. (2-sided) \\
\hline Pearson Chi-Square & 1.274 & 2 & 0.529 \\
\hline B. Use of cash budgets & No & Yes & Total \\
\hline Distressed & 5 & 10 & 15 \\
\hline Not Distressed & 3 & 14 & 17 \\
\hline Total & 8 & 24 & 32 \\
\hline & Value & $d f$ & Asymp. Sig. (2-sided) \\
\hline Pearson Chi-Square & 1.046 & 1 & 0.306 \\
\hline C. Use of ZBB & No & Yes & Total \\
\hline Distressed & 6 & 9 & 15 \\
\hline Not Distressed & 8 & 9 & 17 \\
\hline
\end{tabular}




\begin{tabular}{|c|c|c|c|c|}
\hline \multicolumn{2}{|c|}{ Total } & & & 32 \\
\hline & & Value & df & Asymp. Sig. (2-sided) \\
\hline \multicolumn{2}{|c|}{ Mann-Whitney U } & 111.00 & & 0.47 \\
\hline D. Use of Ratio Analysis & Not familiar with term used & No & Yes & Total \\
\hline Distressed & 2 & 8 & 5 & 15 \\
\hline Not Distressed & 0 & 9 & 8 & 17 \\
\hline Total & 2 & 17 & 13 & 32 \\
\hline & Value & df & Asymp. Sig. (2-sided) \\
\hline \multicolumn{2}{|c|}{ Pearson Chi-Square } & & 1 & 0.27 \\
\hline \multicolumn{2}{|c|}{ E. Use of Separate Finance Sub-committee? } & No & Yes & Total \\
\hline \multicolumn{2}{|l|}{ Distressed } & 12 & 3 & 15 \\
\hline \multicolumn{2}{|l|}{ Not Distressed } & 4 & 13 & 17 \\
\hline \multirow{2}{*}{\multicolumn{2}{|c|}{ Total }} & 16 & 16 & 32 \\
\hline & & Value & df & Asymp. Sig. (2-sided) \\
\hline \multicolumn{2}{|c|}{ Pearson Chi-Square } & 10.165 & 1 & 0.001 \\
\hline
\end{tabular}

Table 15: Bi-variate Logit analysis of Financial Status Using Size and Finance Sub-Committee as Explanatory Variables

\begin{tabular}{|cc|c|c|c|c|c|c|}
\hline \multicolumn{2}{|c|}{ Variables in the Equation } & B & S.E. & Wald & df & Sig. & Exp(B) \\
\hline \multirow{3}{*}{ Step 1a } & total_expenditure & 1.498 & .904 & 2.745 & 1 & .098 & 4.471 \\
& sub_comittee & 2.025 & .919 & 4.854 & 1 & .028 & 7.579 \\
& Constant & -3.579 & 1.692 & 4.472 & 1 & .034 & .028 \\
\hline
\end{tabular}

a. Variable(s) entered on step 1: total_expenditure, sub_comittee.

\section{Conclusion}

The small sample size of this study means that these findings can only be viewed as exploratory in nature, nevertheless this study makes several important contributions to our understanding of financial management in NPOs. The primary finding of the study was that the majority of NPOs surveyed employed accepted financial management practices and that no relationship between their overall use and an NPO's financial vulnerability was evident. The age and size of the NPO, however, and the Financial Manager's experience were found to be significant in determining the likelihood of financial distress but the use of purchasing procedures, cash budgets, ZBB, and ratio analysis, were not significant. The level of operating reserves and the presence of a separate finance sub-committee were also found to be significant, although caution must be exercised in interpreting these results as it is not possible to infer causation between financial status and cash reserves and the significance of a separate finance-committee may be related to the size of the NPO. Nevertheless these results are suggestive of the importance of sufficient cash reserves and of independent financial oversight for the financial sustainability of an NPO and provide valuable empirical evidence regarding sound NPO management practice. Further research needs to be done to fully explore the links between these variables and financial sustainability but this study provides a good starting point and suggests a viable way forward for designing such research.

Contrary to our expectations, the extent to which NPOs relied on international funding was not found to increase their likelihood of having experienced financial distress post the global financial crisis. Due to the small sample size and the study's narrow geographic focus, however, it is not possible to generalise this finding to all NPOs. It is possible that this result is biased by the number of smaller NPOs in the sample who are less likely to be able to access international funding. Two years may also be an insufficient period for the effects of the financial recession to be fully felt if funders honour their existing financial commitments but fail to renew their funding when it expires. Further research is thus required regarding the relationship between financial sustainability and sources of funding for South African NPOs.

NPOs play a major role in addressing a variety of social challenges and yet relatively little research has been done regarding their financial management and sustainability. A greater theoretical and empirical understanding of NPOs' financial management offers the promise of improving their effectiveness. This study provides a starting point for further research on this important topic by identifying a number of factors which impact on NPOs' financial viability and suggesting productive areas for further research. 


\section{References}

Abraham, A. (2006). 'Financial Management in the Nonprofit Sector: A Mission-Based Approach to Ratio Analysis in Membership Organization.' The Journal of American Academy of Business. 9(2); 212-217.

Anthony, R. N., and Young, D. W. (1999). Management Control in Nonprofit Organizations. New York: McGraw-Hill.

Bird, P. (1985). 'The Level of Reserves in Fund-Raising Charities'. Financial Accountability \& Management. 1(2); 161-171.

Blazek, J. (2008). Nonprofit Financial Planning Made Easy. New Jersey: John Wiley \& Sons.

Copeland, T. E., and Smith, K. V. (1978). 'An Overview of Nonprofit Organizations'. Journal of Economics and Business. $30 ; 21$ - 27.

Department of Social Development. 2005. Assessment of NPO Act. Pretoria: Government Printer.

Department of Social development Annual Report. (2009). [Online] Available: http://www.info.gov.za/view/ DownloadFileAction?id=108498 (Accessed 18 February 2010).

Evans, M.H. (2010). Excellence in Financial Management. Course 15: Creating Value in the Nonprofit Sector. [Online] Available: http://www.exinfm.com/training/ [Accessed: 07 July 2010].

Gaertner, J. (1982). 'Cash Budgets.' In: Connors, T., and Callaghan, C. Financial Management for Nonprofit Organizations. pp. 57 - 64. New York: American Management Associations.

Goddard, A. and Assad, M.J. (2006). 'Accounting and navigating legitimacy in Tanzanian NGOs'. Accounting, Auditing \& Accountability Journal. 19(3); 377-404.

Grønbjerg, K. and Clerkin, R. (2004). Indiana Nonprofits: Managing Financial and Human Resources. Nonprofit Survey Series Report No. 4. [Online] Available: http://www.indiana.edu/ nonprof/results/npsurvey/insman1.pdf

Grønbjerg, K.; Cheney, L.; Leadingham, S. and Liu, H. (2007). 'Nonprofit Capacity Assessment: Indiana Charities, 2007'. Nonprofit Capacity Assessment Survey Series, Report \#1, (Bloomington, IN: Indiana University School of Public and Environmental Affairs. [Online] Available: http://www.indiana.edu/ nonprof/results/npcapacity/charitycapacityassessment.pdf

Hankin, J.A., Seidner, A., Zietlow, J. (1997) Financial Management for Nonprofit Organizations. New York: John Wiley \& Sons.

Krug, K. and Weinberg, C.B. (2004). 'Mission, Money, and Merit: Strategic Decision Making by Nonprofit Managers'. Nonprofit Management \& Leadership. 14(3); 325-342.

LeRoux, K.M. (2005). "What Drives Nonprofit Entrepreneurship? A look at budget trends of Metro Detroit Social Services Agencies". American Review of Public Administration. 35(4); 350-362.

Pajas, P., and Vilain, M. (2004). Finance of Nonprofit Organizations. In Zimmer, A. and Priller, E. Future of Civil Society: Making Central European Nonprofit Organizations Work. Weisbaden, Germany: V.S. Verlag fur Sozialwissenschaften.

York, P. (2009). The Sustainability Formula: How Nonprofit Organizations Can Thrive in the Emerging Economy. New York: TCC Group.

Zietlow, J. T. (1989) 'Capital and Operating Budgeting Practices in Pure Nonprofit Organizations'. Financial Accountability and Management. 5(4): $219-232$.

Zietlow, J. T., and Seidner, A. G. (2007). Cash \& Investment Management for Nonprofit Organizations. New Jersey: John Wiley \& Sons, Inc.

Zietlow, J. T., Hankin, J. A., and Seidner, A. G. (2007). Financial management for nonprofit organizations: policies and practices. New Jersey: John Wiley \& Sons, Inc. 